\title{
Risk of myocardial infarction and cardiovascular death associated with inhaled corticosteroids in COPD
}

\author{
Y.K. Loke*, C.S. Kwok ${ }^{\#}$ and S. Singh"
}

ABSTRACT: The effect of long-term inhaled corticosteroid (ICS) use on myocardial infarction (MI) and cardiovascular (CV) death in chronic obstructive pulmonary disease (COPD) remains uncertain.

We conducted a systematic search of MEDLINE, EMBASE, ISI, regulatory documents and manufacturers' trial registries for long-term ( $>24$ weeks duration) randomised controlled trials (RCTs) or controlled observational studies reporting on CV outcomes or death with ICS use in COPD. A fixed effects model was used to calculate the relative risks (RRs) and $95 \%$ Cls.

23 RCTs with 24-160 weeks of follow-up were included. In the RCTs, ICS were not associated with a significantly reduced risk of $\mathrm{MI}$ (RR $0.95,95 \% \mathrm{Cl} 0.73-1.23 ; \mathrm{p}=0.68, \mathrm{I}^{2}=0 \%$ ), CV death (RR 1.02; 95\% Cl 0.81-1.27; $p=0.89, \mathrm{I}^{2}=0 \%$ ), or mortality (RR $0.96,95 \% \mathrm{Cl} 0.86-1.07 ; \mathrm{p}=0.43, \mathrm{I}^{2}=0 \%$ ). In the observational studies, ICS use was associated with a significant reduction in CV death (two studies: RR $0.79,95 \% \mathrm{Cl} 0.72-0,86 ; \mathrm{p}<0.0001, \mathrm{I}^{2}=44 \%$ ) and mortality (11 studies: $\mathrm{RR} 0.78,95 \% \mathrm{Cl}$ $0.75-0.80 ; p<0.001, I^{2}=33 \%$ ). Publication bias via funnel plot asymmetry was noted for mortality in the observational studies (Egger test, $\mathrm{p}=\mathbf{0 . 0 5}$ ).

We conclude that while observational studies suggest that ICS may potentially confer CV or mortality benefit, RCTs failed to show any significant effect of ICS therapy on MI or CV death. These conflicting findings need to be clarified through further research.

KEYWORDS: Cardiovascular effects, chronic obstructive pulmonary disease, inhaled corticosteroids, meta-analysis, mortality

nhaled corticosteroids (ICS) such as fluticasone propionate, budesonide and beclometasone are widely used in chronic obstructive pulmonary disease (COPD) [1]. According to the current Global Initiative for Chronic Obstructive Lung Disease guidelines, ICS are indicated in combination with long acting $\beta_{2}$-agonists (LABA) in patients with moderate-to-severe COPD to reduce the frequency of exacerbations [2].

ICS may potentially reduce cardiovascular (CV) events by alleviating the systemic inflammation responsible for atherogenesis in patients with COPD [3]. CV and mortality benefits with ICS have been reported in observational studies in patients with COPD $[4,5]$. However, it remains uncertain whether this beneficial effect is seen in randomised controlled trials (RCTs). CV disease is an important cause of morbidity and mortality among patients with COPD [6]. The strength of association between ICS use and CV events and mortality and the magnitude of any potential benefit needs critical evaluation.

Our primary objective was to systematically ascertain the risk of myocardial infarction (MI) or CV death associated with long-term use of ICS compared with control therapies in COPD. As a secondary objective, we aimed to ascertain the effects of ICS on overall mortality.

\section{METHODS}

\section{Inclusion criteria}

Our inclusion criteria for RCTs were as follws: 1) a study design consisting of parallel-group RCTs for any ICS (fluticasone, beclomethasone, budenoside or triamcinolone) of $\geqslant 24$ weeks duration; 2 ) study participants with COPD of any severity; 3 ) an ICS as the intervention drug versus control treatment, in which the comparison groups consisted of ICS versus placebo or ICS in combination with LABA

\section{AFFILIATIONS}

*Dept of Clinical Pharmacology,

\#School of Medicine, University of East Anglia, Norwich, UK.

'Dept of Medicine, Johns Hopkins University School of Medicine, Baltimore, MD, USA.

CORRESPONDENCE S. Singh

Section on General Internal Medicine, Dept of Medicine

Johns Hopkins University School of Medicine; Suite 8063

E 1830 Monument St

Baltimore

MD 21287

USA

E-mail: ssingh31@jhu.edu

Received:

June 172009

Accepted after revision:

Nov 062009

First published online:

Nov 192009 
versus LABA alone; and 4) the trials had to explicitly report data (including zero events) on the incidence of MI, CV death or overall mortality.

Controlled observational studies (case control, prospective cohort or retrospective cohort) reporting on MI or mortality with ICS exposure compared to those without ICS exposure in COPD were also evaluated.

\section{Exclusion criteria}

We restricted the analysis of RCTs to trials of $>24$ weeks duration to evaluate the long-term CV effects of ICS use. RCTs in patients with asthma or acute exacerbations of COPD were excluded.

\section{Search strategy}

An initial search which yielded 30 long-term RCTs of ICS from 651 citations was originally carried out in May 2008 as part of an earlier systematic review [7], covering PubMed and EMBASE by using the clinical trial filters in conjunction with drug and disease search terms ("fluticasone" or "budesonide" or "beclometasone" or "beclomethasone") and "chronic" and "obstructive". Y.K. Loke and C.S. Kwok continued updating the search until April 30, 2009, and added the drug term "triamcinolone" to the above trial search with no language restrictions. A separate search string was used to identify observational studies: "inhaled corticosteroids" AND "cohort OR case-control" AND "mortality OR death OR myocardial OR cardiovascular" AND "chronic obstructive". Published and unpublished trials were retrieved from the Cochrane Database of systematic reviews, websites of the US Food and Drug Administration, European regulatory authorities, manufacturers' product information sheets and the manufacturers' clinical trials register of fluticasone and beclometasone (GlaxoSmithKline) [8], and budesonide (AstraZeneca) [9]. The bibliographies of included studies and the Web of Science Cited References search were used to identify relevant citing articles.

\section{Study selection}

Two reviewers (Y.K. Loke and C.S. Kwok) independently and in duplicate scanned all titles and abstracts that indicated the study was an RCT or observational study evaluating the use of ICS in patients with COPD. After obtaining full reports of potentially relevant RCTs and observational studies, the same two reviewers independently assessed eligibility from full text articles. Full consensus regarding eligibility and matching between journal publications and company trial reports was obtained after consultation with a third reviewer (S. Singh).

\section{Study characteristics}

A pre-specified protocol was used to record: the location and duration of the RCT (in weeks); the spirometric criteria used to diagnose COPD in participants; the primary outcome measure; the dose and frequency of ICS and control interventions; mean age and sex of participants; the severity of COPD in the participants as mean predicted forced expiratory volume in $1 \mathrm{~s}$ (FEV1); previous ICS corticosteroid use; and the proportion of current smokers and patients with pre-existing CV disease or $\mathrm{CV}$ risk factors when available. The design and relevant data sources, duration of follow-up, the number of study participants and their selection criteria were recorded for the observational studies.

\section{Risk of bias assessment}

Two reviewers independently and in duplicate assessed the reporting of blinding, allocation concealment, withdrawals and the loss to follow-up in RCTs. To determine the strength of adverse event monitoring, the frequency and type of adverse event monitoring during the follow-up period were evaluated based on the recommendations in the Cochrane Handbook for Systematic Reviews of Interventions on assessing adverse effects [10]. Information on the selection of participants, the comparability of cases and controls, and methods used in ascertaining exposure and outcomes, and the sources of support were extracted for the observational studies. The risk of publication bias was assessed using funnel plot and Egger's test. Evidence of asymmetry from Egger's test was considered to be a p-value $<0.1$ [11].

\section{Outcome measures}

The end-points of incidents of fatal and nonfatal MI and CV death were pre-specified as the co-primary outcome measures. A composite CV mortality end-point comprising of fatal MI, fatal stroke, sudden death, cardiac arrest and fatal arrhythmias was constructed for trials that did not report on the specific end-point of $\mathrm{CV}$ death but provided mortality data on individual CV end-points [12]. The CV end-points were ascertained through routine serious adverse events (life threatening, require hospitalisation or lead to significant disability or death) reported within each trial and may not have been prospectively defined in a uniform fashion across the trials, because none of the RCTs were prospectively designed to assess the CV risk of ICS use. The end-point of all-cause mortality or overall mortality (inclusive of CV death) was pre-specified as the secondary outcome measure.

\section{Data extraction}

Two reviewers independently and separately extracted data (including zero events) on MI, CV death and mortality among trial listings of adverse events or serious adverse events. Data in the clinical trials register and the regulatory documents were reconciled with data in the published journal article when possible, and authors were contacted for data clarification where needed. If there were multiple reports for a particular study, data from the recent versions were extracted. We avoided double counting of trials by cross checking published and unpublished studies. We extracted the crude and adjusted risk ratios for $\mathrm{CV}$ events and mortality from the observational studies. Two reviewers (Y.K. Loke and C.S. Kwok.) were independently involved in all stages of study selection, data extraction and risk of bias assessment. Discrepancies were resolved with $100 \%$ agreement after rechecking the source papers, further discussion among the reviewers, and consultation with a third reviewer (S. Singh), with full consensus obtained before drafting the article.

\section{Statistical analysis}

RevMan (version 5.021; Nordic Cochrane Center, Copenhagen, Denmark) was used to calculate relative risk (RR) and 95\% CI for the outcome of MI, CV death and all-cause mortality. Outcome data on trial participants were analysed using a $2 \times 2$ format according to the "intention to treat" principle. All 
reported p-values are two sided with significance set at $<0.05$. Statistical heterogeneity was assessed using the Cochrane $\mathrm{I}^{2}$ statistic, with $\mathrm{I}^{2}>25 \%$ indicating moderate statistical heterogeneity and $\mathrm{I}^{2}>50 \%$ indicating a substantial level of heterogeneity [13]. We planned to pool data across studies using the fixed-effects models if substantial statistical heterogeneity was not present. If substantial statistical heterogeneity was present $\left(\mathrm{I}^{2}>50 \%\right)$, we planned to explore sources of heterogeneity and the effect of individual study characteristics and subgroups on the risk estimates.

A predefined sensitivity analyses was performed to explore the influence on effect size of the choice of comparators, statistical models (fixed versus random effects), duration of the trials (limited to the trials $>1 \mathrm{yr}$ in duration), and the risk of bias by restricting the analysis to RCTs at low risk of bias (adequate sequence generation, allocation concealment and double-blinding, with clear reporting of loss to follow-up). We evaluated the effect of ICS dose by excluding data from intervention arms where participants were randomised to lower doses of ICS (fluticasone $\leqslant 500 \mu \mathrm{g}$ daily and budesonide $\leqslant 400 \mu \mathrm{g}$ daily).

Risk ratios (RR or hazard ratio, adjusted where available) from the observational studies were pooled separately from the RCTs, using the generic inverse variance method with fixed effects model. We assumed similarity between the risk ratio and OR because $\mathrm{CV}$ events and deaths were assumed to be rare events [14].

\section{RESULTS}

\section{Trial characteristics}

The flow chart of study selection is shown in figure 1 . Of the 715 citations retrieved, 23 RCTs fulfilled our inclusion criteria [1537]. Trial characteristics are shown in table 1 . These trials enrolled a total of 23,396 participants with COPD, with 12,332 receiving ICS versus 11,064 controls. The duration of the trials ranged from 24 to 160 weeks, with 16 trials being longer than 52 weeks in duration [15-20, 22, 23, 25, 27-29, 32, 33, 36, 37]. The sample size was variable and the number of participants in the trials ranged from 186 [23] to 6,184 [18]. Inhaled fluticasone was evaluated in 16 trials [15-18, 20-27, 30, 31, 35, 37], inhaled budesonide in six trials [19, 28, 32-34, 36], and inhaled triamcinolone in only one trial [29]. Most trials enrolled participants with severe COPD, as the mean FEV1 of the participants was $<50 \%$ for the majority of trials, compared to $>50 \%$ for only a few trials $[28,29,35]$. The majority of the participants were males, with proportions of current smokers ranging from $22 \%$ [35] to $90 \%$ [29]. COPD was consistently defined in the RCTs with spirometric criteria and the majority of trials excluded patients with asthma, except the Lung Health Study [29] which had $<10 \%$ of participants with asthma in both arms. The trial by PAGGIARO et al. [31] had some patients with atopy [31], while SCO40041 [23] and SCO3002 did not specify these exclusions [25].

The trial quality was variable (table 2). All the RCTs had blinding of participants and personnel [15-37]. The loss to

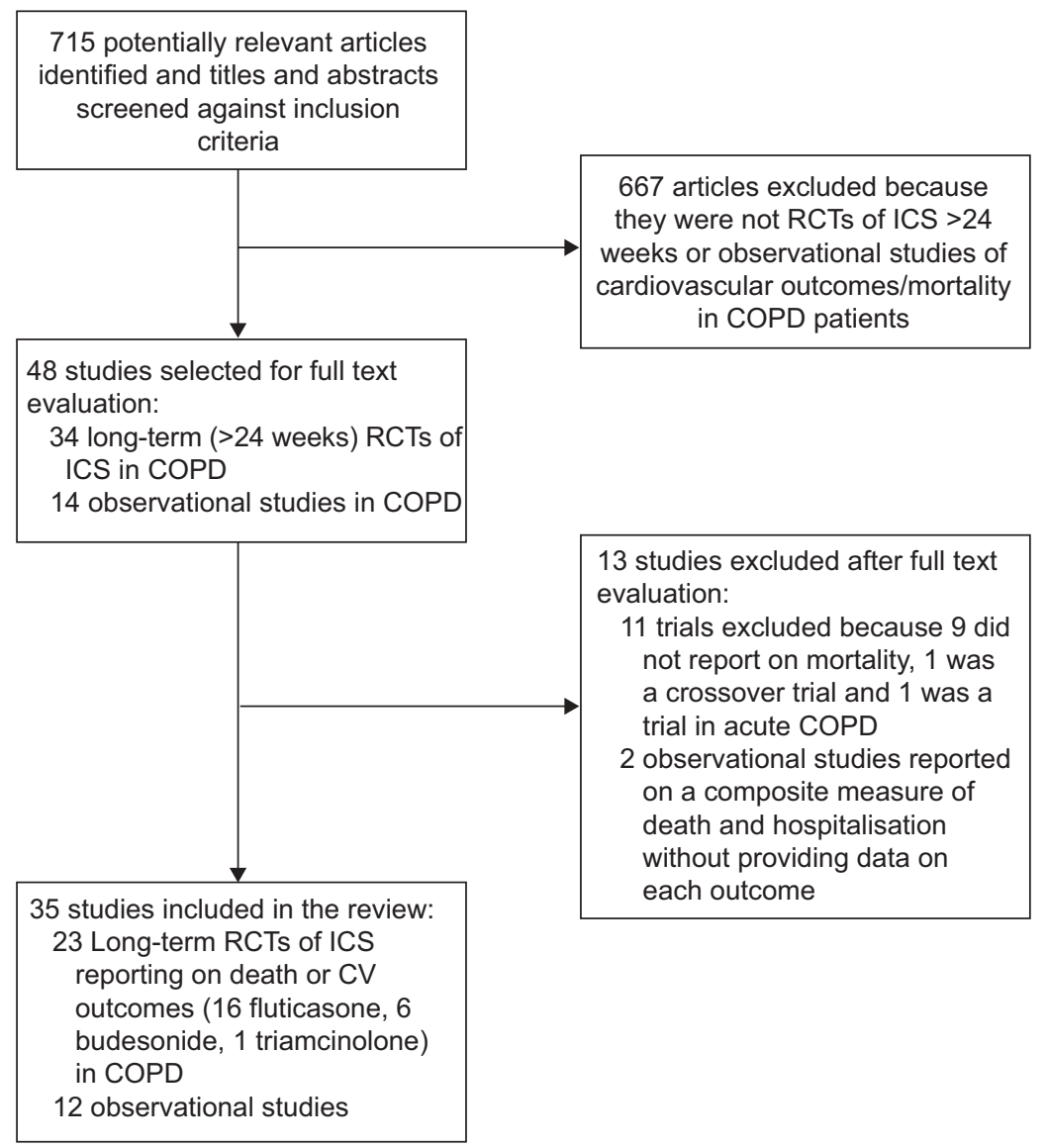

FIGURE 1. Flow chart showing the study selection. RCTs: randomised controlled trials; ICS: inhaled corticosteroids; COPD: chronic obstructive pulmonary disease; $\mathrm{CV}$ : cardiovascular. 


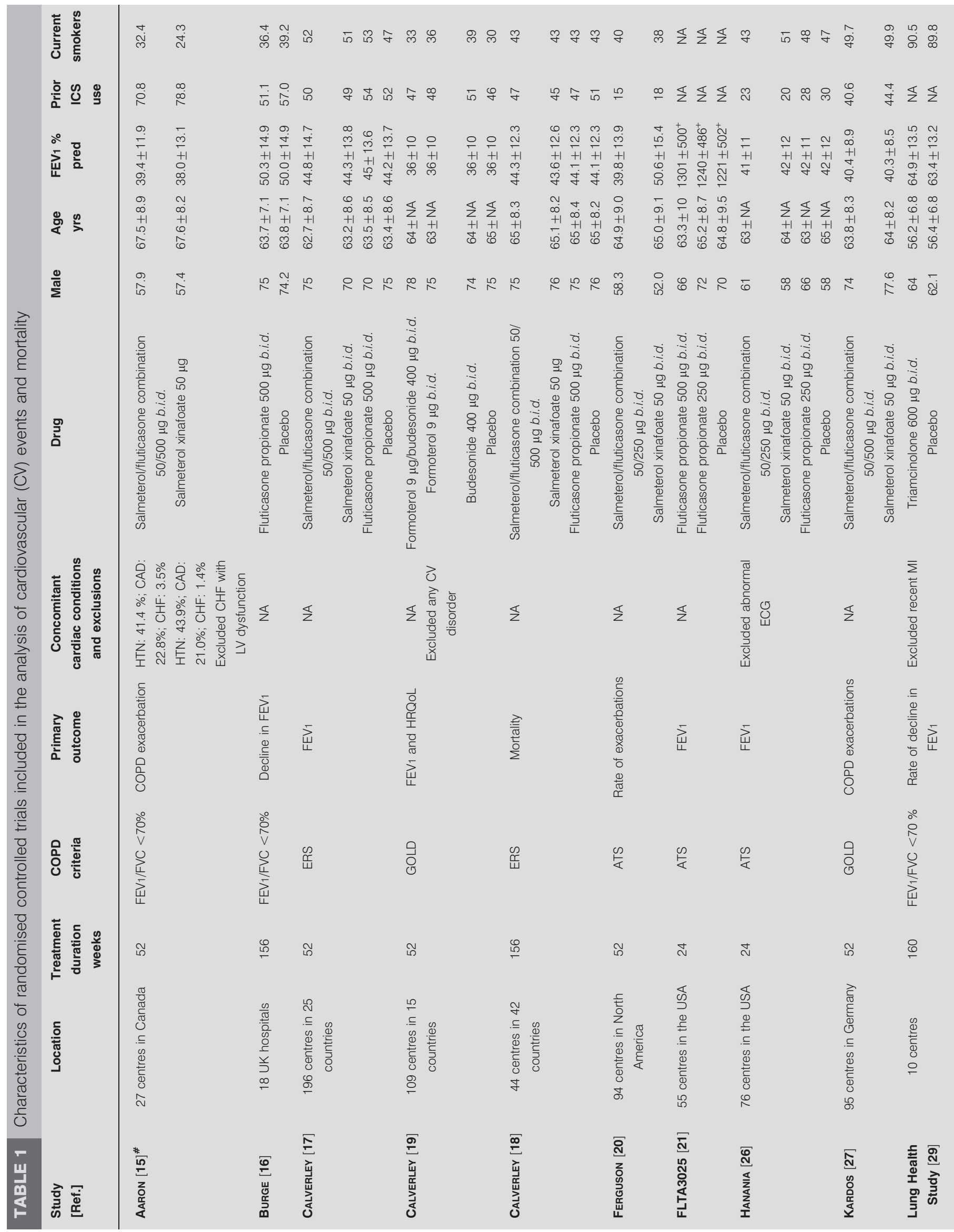




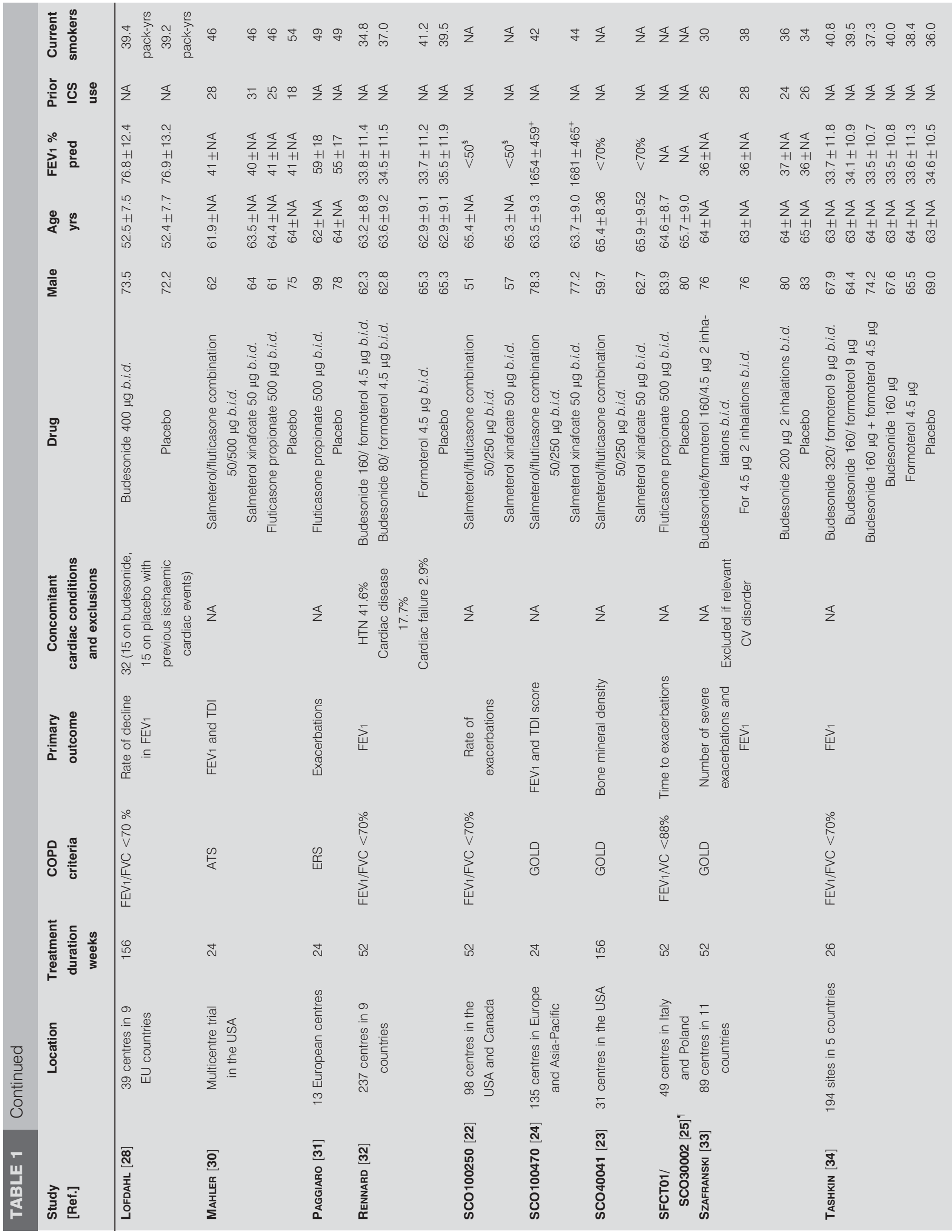




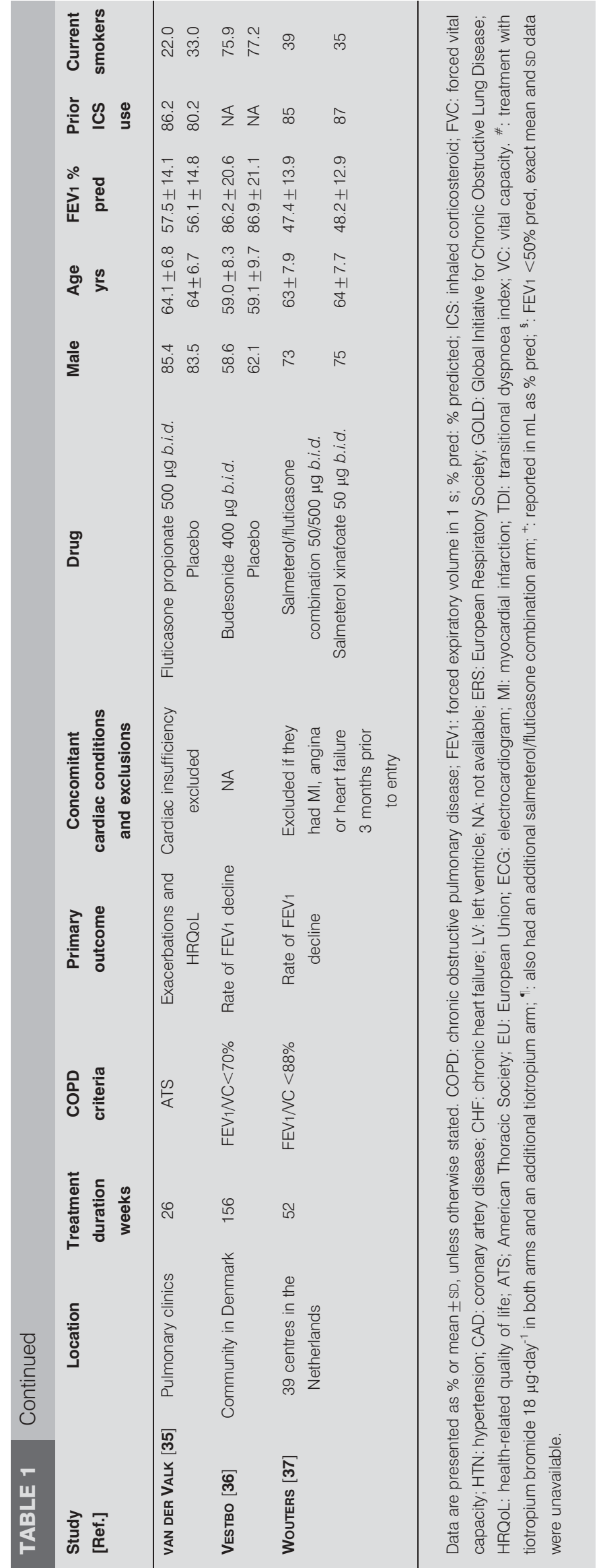

follow-up was variable and ranged from no loss to follow-up (0\%) [35-37] to $4.9 \%$ [16]. Similarly, the withdrawal rates were variable and ranged from $<1 \%$ [35] to $52 \%$ [16]. Nine RCTs provided detailed descriptions regarding blinding, adequate sequence generation, allocation concealment, and clear reporting of loss to follow-up and were at low risk of bias [15-18, 27, 31, 35-37]. The remaining 14 RCTs were at unclear risk of bias [19-21, 22-26, 28-30, 32-34]. 23 RCTs reported on overall mortality [15-37], of which 20 trials reported on MI [15-18, 20-28, 30-32, 34-37] and 20 trials reported on CV death [15-18, 20-31, 34-37]. Data on MI, CV death and overall mortality in the RCTs are shown in table 3.

\section{Main findings}

ICS use was not associated with a significant effect on the risk of MI (105 (1.0\%) out of 10,222 versus 107 (1.2\%) out of 8,951 for control; RR 0.95 (95\% CI 0.73-1.23); $\mathrm{p}=0.68$ ) (fig. 2). There was no evidence of statistical heterogeneity among the included trials $\left(\mathrm{I}^{2}=0 \%\right)$ [15-18, 20-28, 30-32, 34-37].

ICS use was not associated with a significant effect on the risk of CV death (149 (1.8\%) out of 8,274 versus 145 (1.9\%) out of 7,705 for control; RR 1.02 (95\% CI 0.81-1.27); $\mathrm{p}=0.89$ ) (fig. 3). There was no evidence of statistical heterogeneity among the included trials $\left(\mathrm{I}^{2}=0 \%\right)$ [15-18, 20-31, 34-37].

ICS use was not associated with a significant effect on the risk of mortality (580 (5.2\%) out of 11,241 versus 596 (5.8\%) out of 10,211 for control; RR 0.96 (95\% CI 0.86-1.07); p=0.43) [15-37]. There was no evidence of statistical heterogeneity among the included trials $\left(\mathrm{I}^{2}=0 \%\right)$.

\section{Sensitivity analysis}

These estimates were robust to the choice of comparators in subgroup analysis. ICS use was not associated with a significant effect on the risk of MI when combined ICS+LABA was compared to LABA alone (RR 0.92 (95\% CI 0.63-1.35), $\mathrm{p}=0.67$; $\mathrm{I}^{2}=0 \%$ ) or when ICS was evaluated against placebo (RR 0.97 (95\% CI 0.67-1.40), $\mathrm{p}=0.87 ; \mathrm{I}^{2}=0 \%$ ). Similarly, ICS use was not associated with a significant effect on the risk of $\mathrm{CV}$ death when combined ICS+LABA was compared to LABA alone (RR 1.12 (95\% CI 0.79-1.58), $\mathrm{p}=0.53 ; \mathrm{I}^{2}=0 \%$ ) or when ICS was evaluated against placebo (RR 0.95 (95\% CI 0.71-1.27), p=0.74; $\mathrm{I}^{2}=0$ ) Combined ICS and LABA use did not significantly reduce MI (RR 1.09 (95\% CI 0.68-1.75), $\mathrm{p}=0.71 ; \mathrm{I}^{2}=0 \%$ ) or $\mathrm{CV}$ death (RR 0.81 (95\% CI 0.58-1.12), $\mathrm{p}=0.20 ; \mathrm{I}^{2}=0 \%$ ) against placebo. The random effects analysis on MI (RR 0.92 (95\% CI $0.70-1.20)$, $\mathrm{p}=0.52 ; \mathrm{I}^{2}=0 \%$ ) and CV death (RR 1.01 (95\% CI $0.81-1.27$ ), $\left.\mathrm{p}=0.90 ; \mathrm{I}^{2}=0 \%\right)$ associated with ICS use yielded effect sizes similar in magnitude and direction to those from the fixedeffects analysis.

The sensitivity analysis on MI (RR 0.95 (95\% CI 0.72-1.24), $\mathrm{p}=0.70 ; \mathrm{I}^{2}=0 \%$ ) and $\mathrm{CV}$ death (RR 1.02 (95\% CI $\left.0.82-1.28\right)$, $\mathrm{p}=0.84 ; \mathrm{I}^{2}=2 \%$ ) associated with ICS use in trials of $\geqslant 52$ weeks duration [15-20, 22, 23,25 27-29, 32, 33, 36, 37] was similar in magnitude and direction to the overall estimates. The sensitivity analysis on MI (RR 0.91 (95\% CI $\left.0.67-1.24), \mathrm{p}=0.56 ; \mathrm{I}^{2}=0 \%\right)$ and $\mathrm{CV}$ death (RR $1.00(95 \% 0.79$ 1.25), $\mathrm{p}=0.97 ; \mathrm{I}^{2}=9 \%$ ) associated with ICS use in RCTs at low risk of bias [15-18, 27, 31, 35-37] was similar in magnitude and direction to the overall estimates. The exclusion of trial 
TABLE 2 Risk of bias assessment of included randomised controlled trials of inhaled corticosteroids in chronic obstructive pulmonary disease (COPD) ${ }^{\#}$

\begin{tabular}{|c|c|c|c|c|c|c|}
\hline $\begin{array}{l}\text { Study } \\
\text { [Ref.] }\end{array}$ & $\begin{array}{l}\text { Sequence } \\
\text { generation }\end{array}$ & $\begin{array}{l}\text { Allocation } \\
\text { concealment }\end{array}$ & AE monitoring & Drug & $\begin{array}{l}\text { Withdrawal } \\
\text { rates }\end{array}$ & $\begin{array}{l}\text { Lost to } \\
\text { follow-up }\end{array}$ \\
\hline AARON [15] & $\begin{array}{l}\text { Adequate, central } \\
\text { allocation }\end{array}$ & Adequate & $\begin{array}{l}\text { AE captured by monthly } \\
\text { telephone questionnaire } \\
\text { and checklist }\end{array}$ & $\begin{array}{l}\text { Salmeterol/fluticasone combination }=145 \\
\text { Salmeterol xinafoate }=148\end{array}$ & $\begin{array}{l}15(10.3) \\
20(13.5)\end{array}$ & $\begin{array}{l}2(1.3) \\
2(1.3)\end{array}$ \\
\hline BURGE [16] & $\begin{array}{l}\text { Adequate, computer } \\
\text { generated, stratified } \\
\text { by centre }\end{array}$ & Adequate & $\begin{array}{l}\text { AEs and SAEs recorded } \\
\text { throughout the study }\end{array}$ & $\begin{array}{l}\text { Fluticasone propionate }=372 \\
\qquad \text { Placebo }=370\end{array}$ & $\begin{array}{l}160(43.0) \\
195(52.7)\end{array}$ & $\begin{array}{l}16(4.3) \\
18(4.9)\end{array}$ \\
\hline Calverley [17] & $\begin{array}{l}\text { Adequate, computer } \\
\text { generated }\end{array}$ & Adequate & $\begin{array}{l}\text { AE or SAE occurring } \\
\text { during therapy }\end{array}$ & $\begin{array}{c}\text { Salmeterol/fluticasone combination }=358 \\
\text { Salmeterol xinafoate }=372 \\
\text { Fluticasone propionate }=374 \\
\text { Placebo }=361\end{array}$ & $\begin{array}{l}89(24.9) \\
119(32.0) \\
108(29.0) \\
140(38.8)\end{array}$ & $\begin{array}{l}8(2.2) \\
8(2.2) \\
8(2.1) \\
6(1.7)\end{array}$ \\
\hline Calverley [19] & Unclear & Unclear & $\begin{array}{l}\text { AEs recorded at } 1,2,3,6,9 \\
\text { and } 12 \text { months of treatment }\end{array}$ & $\begin{array}{c}\text { Formoterol } / \text { budesonide }=254 \\
\text { Formoterol }=255 \\
\text { Budesonide }=257 \\
\text { Placebo }=256\end{array}$ & $\begin{array}{l}74(29) \\
111(44) \\
102(40) \\
106(41)\end{array}$ & $\begin{array}{l}4(1.6) \\
4(1.6) \\
4(1.6) \\
6(2.3)\end{array}$ \\
\hline FERGuSON [20] & Unclear & Unclear & AE collected at start and end & $\begin{array}{c}\text { Salmeterol/fluticasone combination }=394 \\
\text { Salmeterol xinafoate }=388\end{array}$ & $\begin{array}{l}117(29.7) \\
149(38.4)\end{array}$ & $\begin{array}{l}10(2.5) \\
10(2.6)\end{array}$ \\
\hline FLTA3025 [21] & Unclear & Unclear & $\begin{array}{c}\text { AEs and SAEs recorded } \\
\text { at each visit }\end{array}$ & $\begin{array}{l}\text { Fluticasone propionate }=434 \\
\text { Placebo }=206\end{array}$ & $\begin{array}{c}147(33.9) \\
79(38.3)\end{array}$ & $\begin{array}{l}\text { NA } \\
\text { NA }\end{array}$ \\
\hline HANANIA [26] & Unclear & Unclear & AE reporting at each visit & $\begin{array}{c}\text { Salmeterol/fluticasone combination }=178 \\
\text { Salmeterol xinafoate }=177 \\
\text { Fluticasone propionate }=183 \\
\text { Placebo }=185\end{array}$ & $\begin{array}{l}53(30) \\
57(32) \\
49(27) \\
59(32)\end{array}$ & $\begin{array}{l}\text { NA } \\
\text { NA } \\
\text { NA } \\
\text { NA }\end{array}$ \\
\hline MAHLER [30] & Unclear & Unclear & AEs and SAEs documented & $\begin{array}{c}\text { Salmeterol/fluticasone combination }=165 \\
\text { Salmeterol xinafoate }=160 \\
\text { Fluticasone propionate }=168 \\
\text { Placebo }=181\end{array}$ & $\begin{array}{l}52(31.5) \\
45(28.2) \\
68(40.5) \\
69(38.1)\end{array}$ & $\begin{array}{l}\text { NA } \\
\text { NA } \\
\text { NA } \\
\text { NA }\end{array}$ \\
\hline PAGgIARO [31] & $\begin{array}{l}\text { Adequate, computer } \\
\text { generated }\end{array}$ & Adequate & $\begin{array}{l}\text { AE defined as untoward } \\
\text { medical occurrence } \\
\text { during treatment }\end{array}$ & $\begin{array}{l}\text { Fluticasone propionate }=142 \\
\text { Placebo }=139\end{array}$ & $\begin{array}{l}19(13.3) \\
27(19.4)\end{array}$ & $\begin{array}{c}0 \\
2(1.4)\end{array}$ \\
\hline RenNaRD [32] & Unclear & Unclear & $\begin{array}{l}\text { AEs, vital signs and ECGs } \\
\text { at study visit }\end{array}$ & $\begin{array}{c}\text { Budesonide } 320 \mu \mathrm{g} / \text { formoterol } 9 \mu \mathrm{g} \\
\text { b.i.d. }=494 \\
\text { Budesonide } 160 \mu \mathrm{g} / \text { formoterol } 9 \mu \mathrm{g} \\
\text { b.i.d. }=494\end{array}$ & $\begin{array}{l}134(27.1) \\
143(28.9)\end{array}$ & $\begin{array}{l}9(1.8) \\
12(2.4)\end{array}$ \\
\hline & & & & $\begin{array}{l}\text { Formoterol }=495 \\
\text { Placebo }=481\end{array}$ & $\begin{array}{l}157(31.7) \\
175(36.3)\end{array}$ & $\begin{array}{l}12(2.4) \\
13(2.7)\end{array}$ \\
\hline SCO100250 [22] & Unclear & Unclear & $\begin{array}{l}\text { AEs and SAEs recorded } \\
\text { after study medication but } \\
\text { no later than last date after } \\
\text { study medication }\end{array}$ & $\begin{array}{l}\text { Salmeterol/fluticasone combination }=394 \\
\text { Salmeterol xinafoate }=403\end{array}$ & $\begin{array}{l}125(31.7) \\
156(38.7)\end{array}$ & $\begin{array}{l}\text { NA } \\
\text { NA }\end{array}$ \\
\hline SC0100470 [24] & Unclear & Unclear & $\begin{array}{l}\text { AEs and SAEs recorded } \\
\text { at each study visit }\end{array}$ & $\begin{array}{c}\text { Salmeterol/fluticasone combination }=518 \\
\text { Salmeterol xinafoate }=532\end{array}$ & $\begin{array}{l}59(11.4) \\
74(13.9)\end{array}$ & $\begin{array}{l}\text { NA } \\
\text { NA }\end{array}$ \\
\hline
\end{tabular}




\begin{tabular}{|c|c|c|c|c|c|c|}
\hline $\begin{array}{l}\text { Study } \\
\text { [Ref.] }\end{array}$ & $\begin{array}{l}\text { Sequence } \\
\text { generation }\end{array}$ & $\begin{array}{l}\text { Allocation } \\
\text { concealment }\end{array}$ & AE monitoring & Drug & $\begin{array}{l}\text { Withdrawal } \\
\text { rates }\end{array}$ & $\begin{array}{l}\text { Lost to } \\
\text { follow-up }\end{array}$ \\
\hline \multirow[t]{2}{*}{ SCO40041 [23] } & Unclear & Unclear & On therapy AEs and & Salmeterol/fluticasone combination $=92$ & $36(39.1)$ & NA \\
\hline & & & SAEs monitored & Salmeterol xinafoate $=94$ & $39(41.5)$ & NA \\
\hline $\begin{array}{l}\text { SFCT01/ } \\
\text { SC030002 [25] }\end{array}$ & Unclear & Unclear & All AEs occurring after subject & Fluticasone propionate $=131$ & $34(26.0)$ & NA \\
\hline \multirow[t]{4}{*}{ SZAFRANSKI [33] } & Unclear & Unclear & AEs detected at visits 2-8, & Budesonide/formoterol=208 & $59(28)$ & NA \\
\hline & & & with ECGs at visits 1,6 and 8 & Formoterol $=201$ & $64(32)$ & NA \\
\hline & & & & Budesonide $=198$ & $62(31)$ & NA \\
\hline & & & & Placebo=205 & $90(44)$ & NA \\
\hline \multirow[t]{3}{*}{ TASHKIN [34] } & Unclear & Unclear & $\begin{array}{c}\text { AEs, vital signs and ECGs } \\
\text { at study visit }\end{array}$ & $\begin{array}{c}\text { Budesonide } 160 \mu \mathrm{g} / \text { formoterol } 4.5 \mu \mathrm{g} \\
\text { b.i.d. }=277\end{array}$ & NA & NA \\
\hline & & & & Formoterol $=284$ & NA & NA \\
\hline & & & & Placebo $=300$ & NA & NA \\
\hline \multirow[t]{2}{*}{ VAN DER VALK [35] } & Adequate, permuted & Adequate & 3- and 6-month follow-up & Fluticasone propionate $=123$ & $1(0.8)$ & 0 \\
\hline & blocks, stratified & & & Placebo $=121$ & $1(0.8)$ & 0 \\
\hline \multirow[t]{2}{*}{ VestBo [36] } & Adequate, computer & Adequate & Participants seen every & Budesonide $=145$ & $36(24.8)$ & 0 \\
\hline & generated & & 3 months & Placebo $=145$ & $51(35.2)$ & 0 \\
\hline \multirow[t]{2}{*}{ WOUTERS [37] } & Adequate & Adequate & AE collected at start and & Salmeterol/fluticasone combination $=189$ & $34(18.0)$ & 0 \\
\hline & & & end of treatment & Salmeterol xinafoate $=184$ & $46(25.0)$ & 0 \\
\hline
\end{tabular}

Data are presented as $n$ or $n(\%)$. AE: adverse event; SAE: serious adverse event; NA: not available; MI: myocardial infarction; CAD: coronary artery disease; ECG: electrocardiogram. ${ }^{*}$ : all randomised controlled trials were double blinded.

arms with lower doses of ICS use did not change the direction or magnitude of the estimates for MI (RR 0.88 (95\% CI $\left.0.66-1.16), \mathrm{p}=0.36 ; \mathrm{I}^{2}=0 \%\right)$ and $\mathrm{CV}$ death (RR $1.03(95 \% \mathrm{CI}$ $\left.0.81-1.28), \mathrm{p}=0.82 ; \mathrm{I}^{2}=5 \%\right)$.

\section{Observational studies}

12 observational studies were included [4, 5, 38-47]. Details of the included studies and the risk of bias are shown in table 4 . Confounding was potentially present in several studies, with differences in baseline characteristics between the study groups [5, 40, 43, 44, 46]. ICS exposure was estimated from dispensing records and dosages were usually extrapolated from the amounts dispensed [39, 43]. It was uncertain if patients with concomitant asthma were reliably excluded (misclassification bias) [40]. Immortal time bias, when patients exposed to ICS had an inappropriate interval of immortality compared with patients exposed to controls that did not have this interval, was a potential bias in certain studies [4, 40, 42-45]. Some studies were funded by manufacturers of ICS [41, 44, 45, 47].

ICS were not associated with a significantly reduced risk of MI (RR 0.83, 95\% CI 0.63-1.08) in one observational study reporting on MI [39]. Two observational studies reported a significant association between ICS exposure and reduction in CV death, but did not specify details on the causes of death $[4,5]$. Pooled analysis of these two studies yielded an RR of 0.79 (95\% CI $0.72-0.86, \mathrm{p}<0.0001)$ for $\mathrm{CV}$ death, with moderate statistical heterogeneity $\left(\mathrm{I}^{2}=44 \%\right.$ ) (fig. $\left.4 \mathrm{a}\right) .11$ observational studies reported on overall mortality [4, 5, 38, 40-47]. ICS use was associated with a significantly reduced risk of death in a meta-analysis of these 11 observational studies (RR 0.78, 95\% CI 0.75-0.80; p<0.0001) (fig. 4b) [4, 5, 38, 40-47]. However, there was evidence of moderate statistical heterogeneity among the included studies $\left(\mathrm{I}^{2}=33 \%\right)$.

\section{Publication bias}

The funnel plot for mortality appeared to be symmetrical for the RCTs (fig. 5a) and showed asymmetry for the observational studies (fig. 5b). The Egger's test for publication bias was nonsignificant for RCTs $(p=0.23)$, with evidence of significant publication bias in the observational studies (Egger's test $\mathrm{p}=0.05)$.

\section{DISCUSSION}

Our meta-analysis has found conflicting evidence on the effects of ICS therapy on cardiovascular events and mortality in patients with COPD. We were unable to demonstrate a significant beneficial effect of ICS therapy on MI or CV death in RCTs. In contrast, our meta-analysis showed significant relative reductions (magnitude of $\sim 20 \%$ ) in the risk of $\mathrm{CV}$ and all-cause mortality with ICS-exposed patients in the observational studies.

\section{Methodological issues}

Publication or outcome reporting bias in the observational studies may partly account for the differences in results between the observational studies and RCTs. The meta-analysis of observational studies was limited to available published studies, and journal publications may favour manuscripts with positive results [48]. In contrast, our meta-analysis of RCTs 
TABLE 3 Cardiovascular (CV) events and all-cause mortality in randomised controlled trials of inhaled corticosteroids in chronic obstructive pulmonary disease

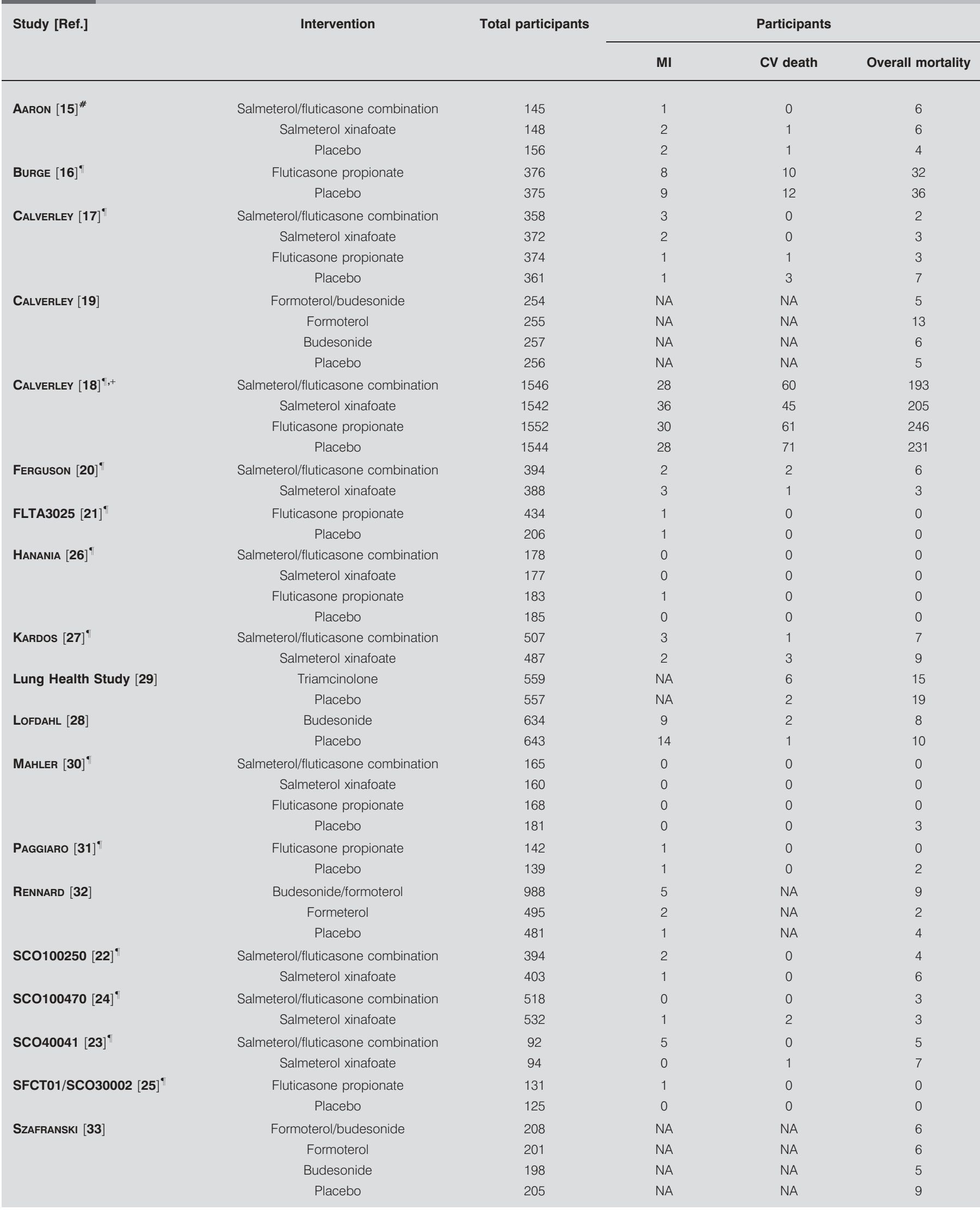




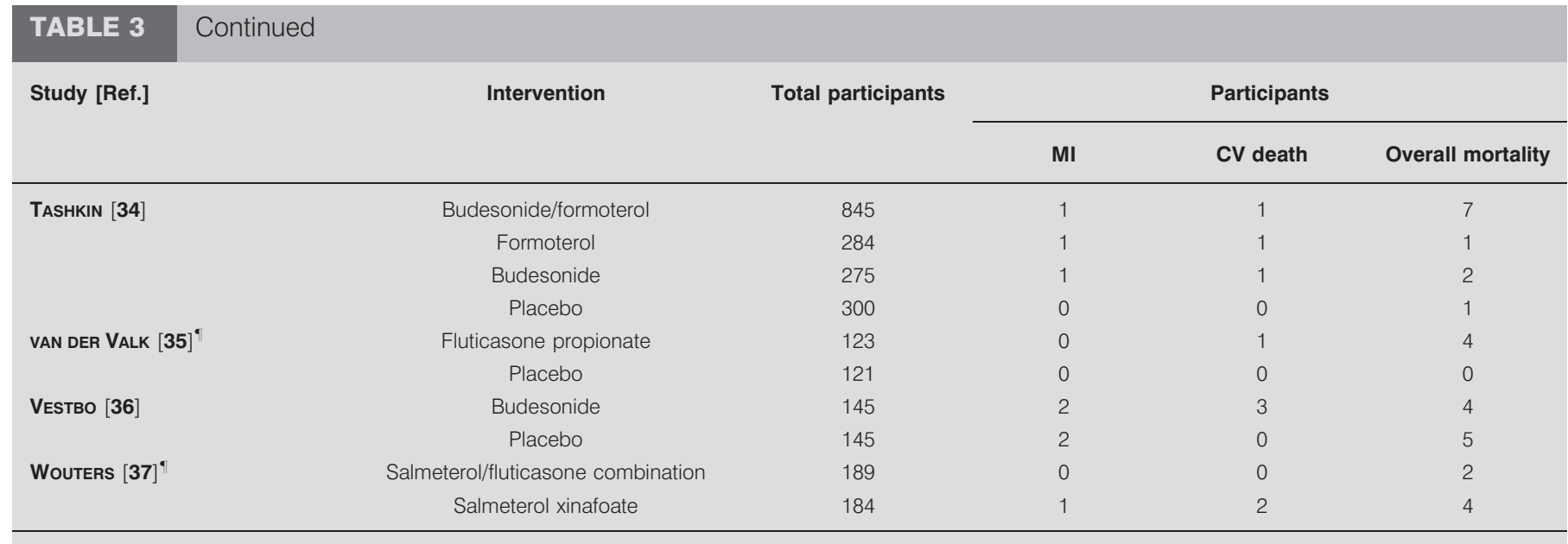

Data are presented as n. MI: myocardial infarction; NA: not available. ${ }^{*}$ : reported as serious adverse event of Ml or acute arrhythmia; ": CV adverse event data extracted from manufacturers clinical trials register; ${ }^{+}$; $\mathrm{CV}$ mortality data extracted from regulatory agencies as unavailable in publications.

included unpublished data from manufacturers' trial registries thus minimising the risk of publication bias.

The presence of immortal time bias may partly account for some of the mortality reduction seen in observational studies, but is not the only explanation for these divergent findings. A time-dependent analysis accounting for the period of ICS exposure versus control exposure (OR 1.00, 95\% CI 0.79-1.26) negated the significant beneficial effect seen using a fixed time analysis (OR 0.69, 95\% CI 0.55-0.86) in a study that measured 90-day mortality [49]. A significant beneficial association, albeit lower in magnitude, was seen with ICS exposure in another study that minimised the risk of immortal time bias [41]. Potential confounders, such as smoking status and lung function, and unknown residual confounding factors, such as co-existing asthma, along with the differential use of home oxygen in patients may have contributed to the perceived effect on mortality in the observational studies.

The apparent lack of CV benefit in the trials which typically exclude patients with serious comorbidities cannot conclusively rule out the potential for a $\mathrm{CV}$ benefit in patients with COPD seen in the observational studies. The rates of concomitant smoking in the observational studies may have been lower than that of RCTs where nearly 50\% of COPD participants had 10 pack-yrs of smoking history. Factors other than smoking, such as biomass, air pollution and poor nutrition, may contribute to the burden of COPD in community patients. Certain subgroups of patients in the observational studies, especially those with severe comorbidities and a higher risk of $\mathrm{CV}$ events, may potentially derive a $\mathrm{CV}$ benefit from ICS use.

\section{Comparisons with previous analysis}

The finding of a lack of CV effect in our intention-to-treat metaanalysis of 23 published and unpublished trials involving 23,396 patients should be distinguished from other metaanalysis of ICS use limited to the published trials. Our metaanalysis had a greater ability to detect any significant difference on mortality with more precise estimates of treatment effect as shown by our relatively narrow 95\% CI
(0.86-1.07) for the RR of overall mortality. An earlier pooled analysis (seven published trials, $n=5,085$, mean duration of follow-up $=26$ months) reported a reduction in mortality with ICS use (adjusted hazards ratio $0.73,95 \%$ CI $0.55-0.96$ ) but had less than one quarter the number of patients than our analysis [50]. The effect was more pronounced in females and former smokers, and the benefits were driven by reduction in cancer deaths [50]. A subsequent Cochrane systematic review which pooled data from nine trials [51], and another recent metaanalysis of five trials found no evidence of a mortality benefit with ICS use [52].

Our failure to detect a significant effect on MI and CV death with ICS (fluticasone, budesonide and triamcinolone) use should be distinguished from a post hoc subgroup analysis of inhaled budesonide versus placebo on ischaemic cardiac events (angina pectoris, coronary artery disorder and MI) in the European Respiratory Society's study on Chronic Obstructive Pulmonary Disease (EUROSCOP) [28]. Their analysis included 1,175 participants, approximately one fifth of the number of participants in our analysis, with mild COPD (average age $52.5 \mathrm{yrs}$ ) and reported a significantly lower risk of ischaemic cardiac events with inhaled budesonide (RR 0.58, 95\% 0.35 $0.98 ; p=0.043)$. The contrasting findings could be partly explained by the inclusion by EUROSCOP of different endpoints of angina, ischaemia and coronary artery disorder in patients with milder COPD. However, applying the end-points of ischaemic cardiac events of EUROSCOP to the similar $3 \mathrm{yr}$ Towards a Revolution in COPD Health (TORCH) trial [18], shows no significant difference in the rate of ischaemic cardiac events in inhaled fluticasone (56 (36.\%) out of 1,552) when compared to placebo $(50(3.2 \%)$ out of 1,544$)$. We did not detect any intraclass differences in the risk of $\mathrm{CV}$ events between inhaled fluticasone and inhaled budesonide in our metaanalysis.

The potential mechanisms by which ICS modulate CV outcomes remain uncertain. ICS could potentially ameliorate $\mathrm{CV}$ disease by reducing exacerbations because acute exacerbation in COPD may precipitate CV disease [53]. The pathology of COPD includes inflammation and/or alterations in repair 


\begin{tabular}{|c|c|c|c|c|}
\hline Study & & & & \\
\hline Ref.] & Events & Total & Events & \\
\hline
\end{tabular}

a) ICS-LABA versus LABA

$\begin{array}{lcc}\text { CALVERLEY [19] } & 3 & 358 \\ \text { WOUTERS [37] } & 0 & 189 \\ \text { SCO100470 [24] } & 0 & 518 \\ \text { AARON [15] } & 1 & 145 \\ \text { CALVERLEY [18] } & 28 & 1546 \\ \text { KARDOS [27] } & 3 & 507 \\ \text { FERGUSON [20] } & 2 & 394 \\ \text { SCO40041 [23] } & 5 & 92 \\ \text { SCO100250 [22] } & 2 & 394 \\ \text { TASHKIN [34] } & 1 & 845 \\ \text { RENNARD [32] } & 5 & 988 \\ \text { Subtotal (95\% CI) } & & 5976 \\ \text { Total events } & 50 & \end{array}$

b) ICS versus placebo

PAGgIARO [31]

Vestbo [36] 2

BURGE [16]

CALVERLEY [17]

HANANIA [26]

FLTA3025 [21]

SFCT01 [25]

Calverley [18]

LOFDAHL [28]

TASHKIN [34]

Subtotal $(95 \% \mathrm{Cl})$

Total events

Total $(95 \% \mathrm{Cl})$

Total events

142
145
376
374
183
434
131
1552
634
275
4246

55

10222

105

$\begin{array}{cc}2 & 372 \\ 1 & 184 \\ 1 & 532 \\ 2 & 148 \\ 36 & 1542 \\ 2 & 487 \\ 3 & 388 \\ 0 & 94 \\ 1 & 403 \\ 1 & 284 \\ 2 & 494 \\ & 4928 \\ 51 & \end{array}$

1.8
1.4
1.3
1.8
32.3
1.8
2.7
0.4
0.9
1.3
2.4
48.1

$1.56(0.26-9.27)$

$0.32(0.01-7.92)$

$0.34(0.01-8.38)$

$0.51(0.05-5.57)$

$0.78(0.48-1.26)$

$1.44(0.24-8.59)$

$0.66(0.11-3.91)$

$11.24(0.63-200.35)$

$2.05(0.19-22.47)$

$0.34(0.02-5.36)$

$1.25(0.24-6.42)$

$0.92(0.63-1.35)$

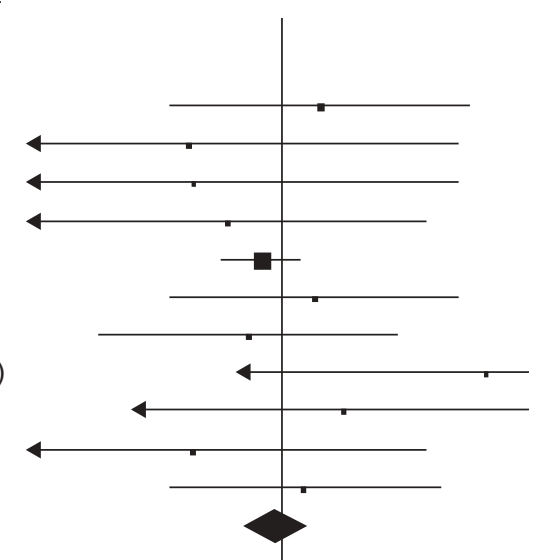

$$
\begin{gathered}
0.98(0.06-15.50) \\
1.00(0.14-7.00) \\
0.89(0.35-2.27) \\
0.97(0.06-15.37) \\
3.03(0.12-73.96) \\
0.47(0.03-7.55) \\
2.86(0.12-69.64) \\
1.07(0.64-1.78) \\
0.65(0.28-1.50) \\
3.27(0.13-79.98) \\
0.97(0.67-1.40)
\end{gathered}
$$

56

51.9

8951

100

107
$0.95(0.73-1.23)$

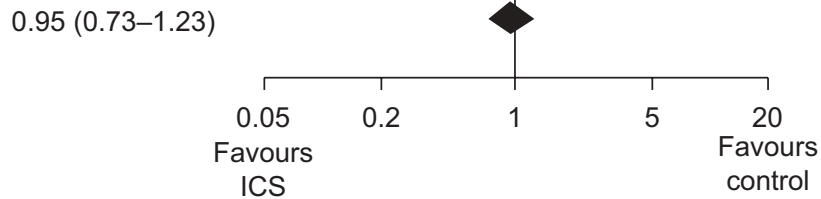

Risk ratio

FIGURE 2. Meta-analysis of randomised controlled trials of inhaled corticosteroids (ICS) versus controls for myocardial infarction. a) ICS-long acting $\beta_{2}$-agonists (LABA) versus $L A B A$ and $b$ ) ICS versus placebo. a) Chi-squared $=6.16$; degrees of freedom $(d f)=10(p=0.80) ; I^{2}=0 \%$. Test for overall effect: $z=0.43(p<0.67)$. b) Chi-squared $=2.79$; $d f=9(p=0.97) ; l^{2}=0 \%$. Test for overall effect: $z=0.16(p<0.87)$. Overall: Chi-squared=9.06; $d f=20(p=0.98) ; l^{2}=0 \%$. Test for overall effect: $z=0.41(p<0.68) . M-H: M a n t e l-$ Haenszel.

mechanisms. The "spill-over" of inflammatory mediators into the systemic circulation in COPD is linked to the development of CV disease [54]. However, ICS use may have limited CV benefit because ICS use does not reduce markers of systemic inflammation (serum CRP or interleukin-6 levels), with little impact on neutrophilic inflammation or matrix remodelling relevant to CV disease in COPD $[54,55]$.

\section{Limitations}

Our meta-analysis has several limitations, which mainly stem from the quality of reported data. The RCTs did not use specific definitions of MI or CV death, and inconsistent adverse events reporting may account for some missing outcome data. Our estimates for $\mathrm{MI}$ and $\mathrm{CV}$ death are relatively imprecise with wide CIs due to the low $\mathrm{CV}$ event rates in the trials. Thus, we cannot rule out the possibility of a relative reduction of $27 \%$ for $\mathrm{MI}$ and $20 \%$ for $\mathrm{CV}$ death with
ICS. 14 trials in the analysis were at unclear risk of bias. The high withdrawal rates in certain trials may also mask any differences in treatment effect. There was potential clinical heterogeneity among the included trials and we cannot completely discount the possibility of statistical heterogeneity because the heterogeneity tests may be underpowered due to low event rates.

We excluded trials shorter than 6 months, but it is unlikely that a substantial CV effect would be discernible in trials of shorter duration. In the absence of patient-level data, we could not determine ICS dose-response relationships [42]. However, the exclusion of lower dose intervention arms did not change the direction or magnitude of the estimates for $\mathrm{MI}$ and $\mathrm{CV}$ death. We could not evaluate the influence of age, severity of COPD, and pre-existing $\mathrm{CV}$ risk factors or concomitant statin [56], or angiotensin inhibitor use on CV events associated with ICS use. 


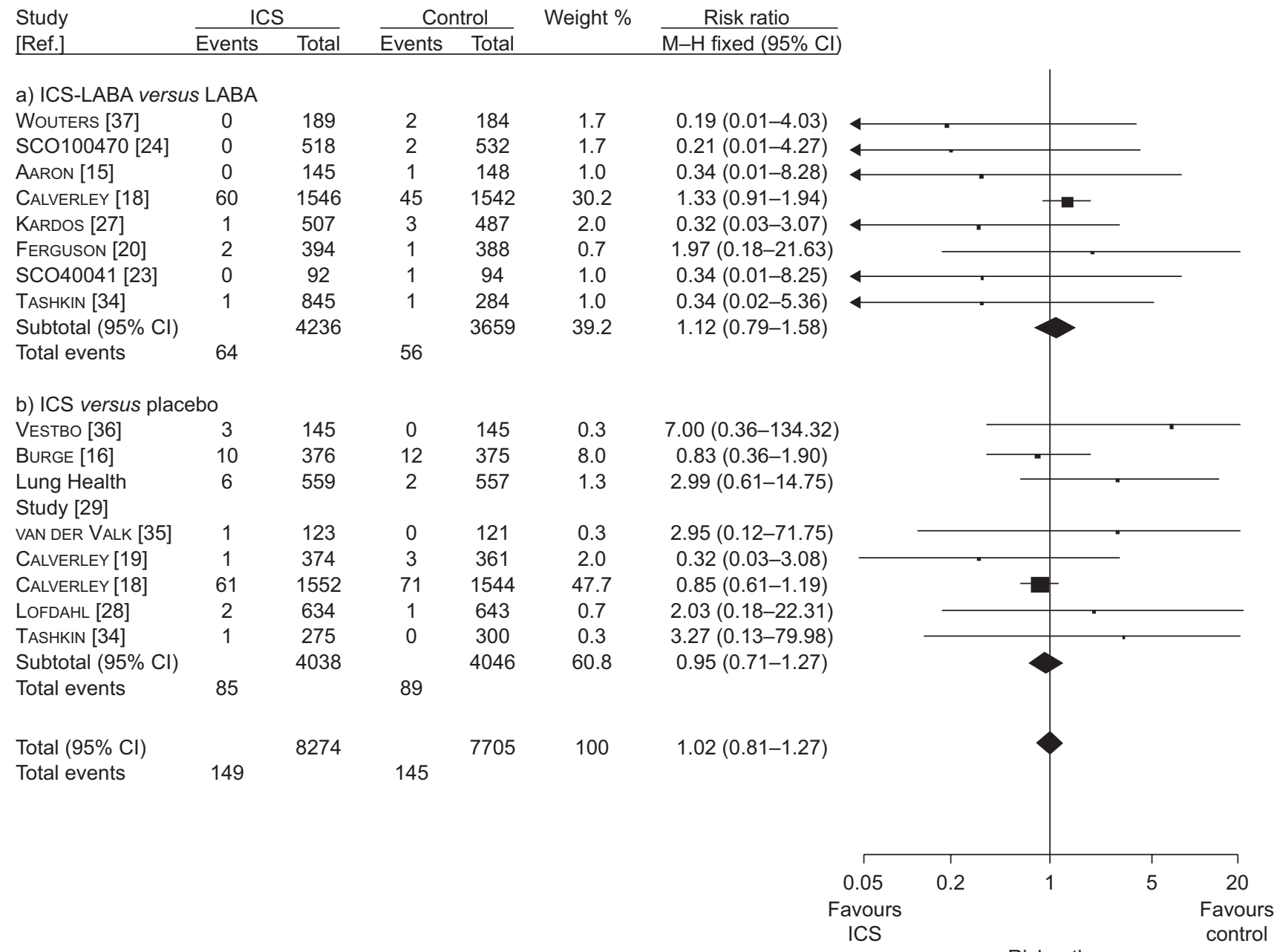

Risk ratio

FIGURE 3. Meta-analysis of randomised controlled trials of inhaled corticosteroids (ICS) versus controls for cardiovascular death. a) ICS-long acting $\beta_{2}$-agonists (LABA) versus LABA and b) ICS versus placebo. a) Chi-squared $=6.46$; degrees of freedom $(\mathrm{df})=7(p=0.49) ;\left.\right|^{2}=0 \%$. Test for overall effect: $z=0.62(p<0.53)$. $\left.b\right) C h i-s q u a r e d=6.55 ; d f=7(p=0.48)$; $I^{2}=0 \%$. Test for overall effect: $z=0.33(p<0.74)$. Overall: Chi-squared $=13.85$; $d f=15(p=0.54) ; l^{2}=0 \%$. Test for overall effect: $z=0.14(p<0.89)$. M-H: Mantel-Haenszel.

Despite these limitations, the apparent absence of improvements in CV and mortality outcomes with ICS use in the trials should be seen in the context of the potential benefit of ICS use on exacerbations, and improved quality of life in recent meta-analyses [51, 57]. Our comprehensive metaanalysis informs the recent debate on the role of ICS in COPD $[58,59]$. RCTs that have reported beneficial effects on exacerbations, but only after a LABA were added to the ICS, were limited by the discontinuation of existing treatment and the absence of the fundamental "intention-to-treat analysis" [60]. Two recent trials [15, 18], designed for a proper intention-to-treat analysis of the primary outcomes, both found no benefit of ICS in COPD [60]. ICS do not reduce the decline in FEV1 in COPD $[2,51]$. The beneficial effect of a LABA-ICS combination may possibly be attributed to the LABA component, without any additional benefit from the addition of an ICS [60].

\section{Future research}

Appropriate factorial analyses evaluating the effect of each component of the LABA-ICS combination inhaler, and re-analysis of patient level data by pre-existing ICS use in trials may clarify the optimal role of ICS use in COPD [61]. A large-scale pragmatic trial in community patients may also help to clarify the CV effects of ICS use.

The benefits of ICS in reducing exacerbations and improving symptoms should be weighed against the potential for harm, such as an increased risk of pneumonia which appears to be limited to inhaled fluticasone [7], but are uncertain for budesonide [62, 63]. Recent data suggest that fluticasone has no significant impact on bone demineralisation [64].

Clinicians will need to carefully evaluate the strengths and limitations of the current evidence concerning the effects of ICS therapy on cardiovascular events when making a treatment decision. Further research to clarify these divergent findings is clearly needed.

\section{SUPPORT STATEMENT}

The design and conduct of the study; the collection, management, analysis and interpretation of the data; and the preparation, review or approval of the manuscript was independent of any sources of 


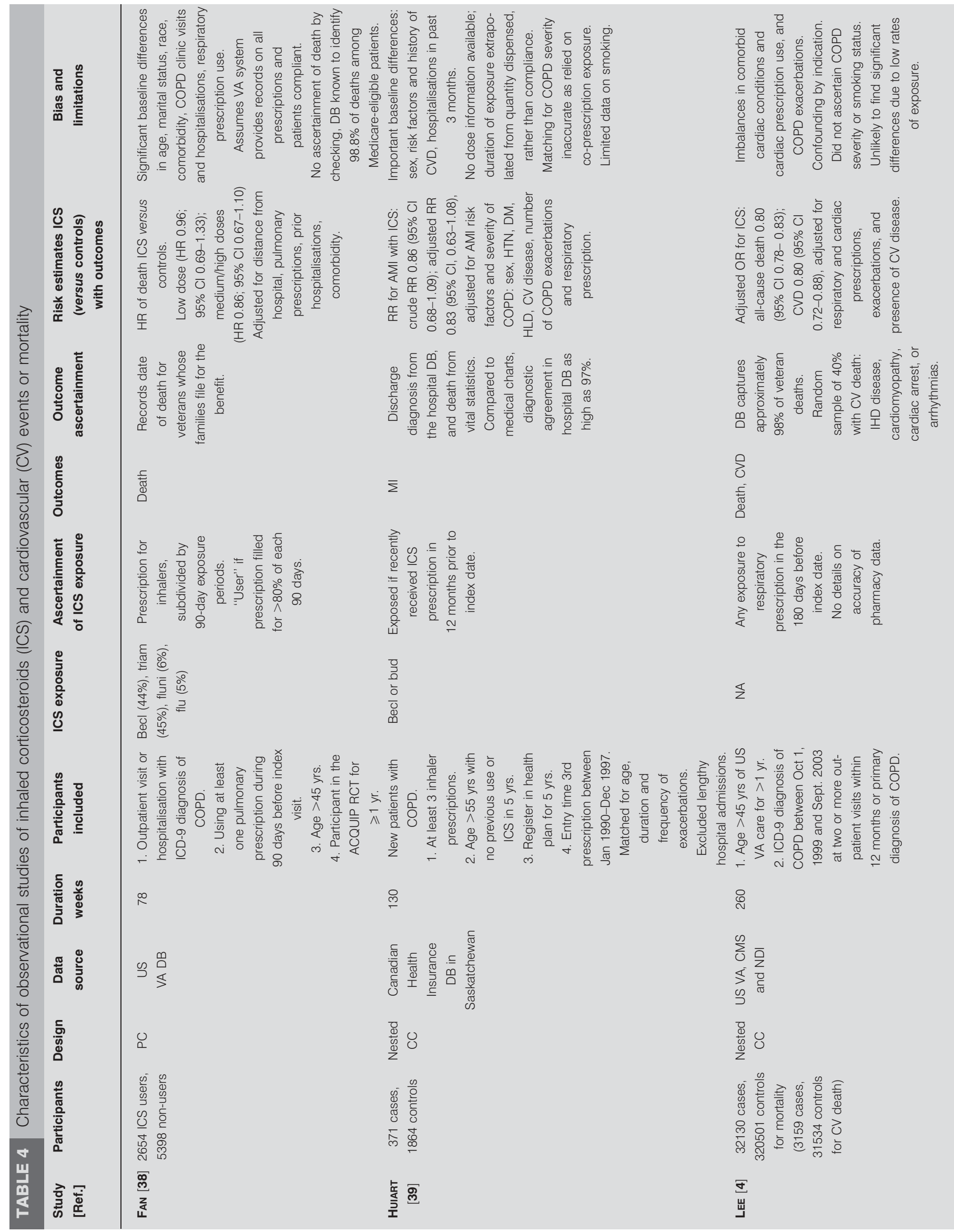




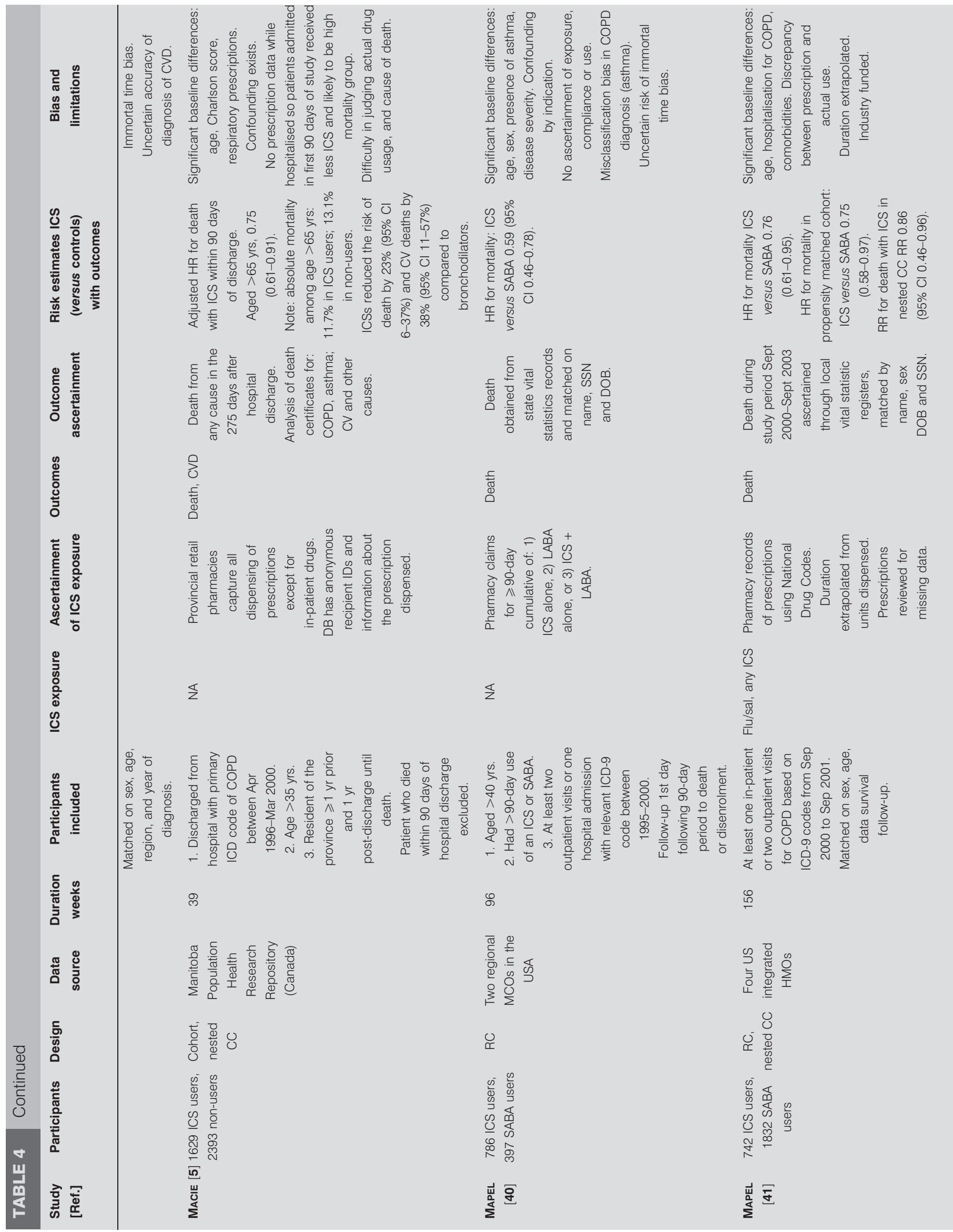




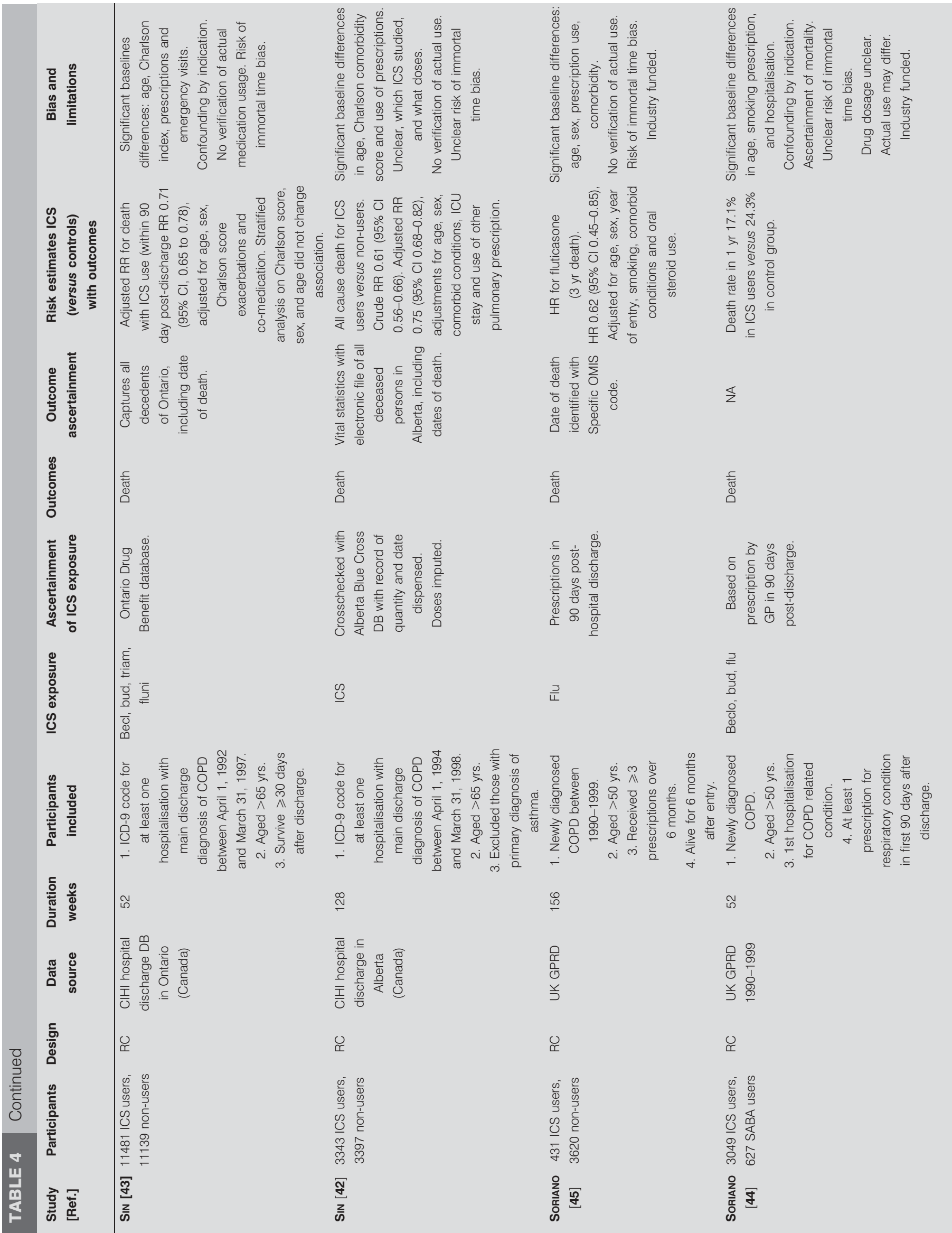




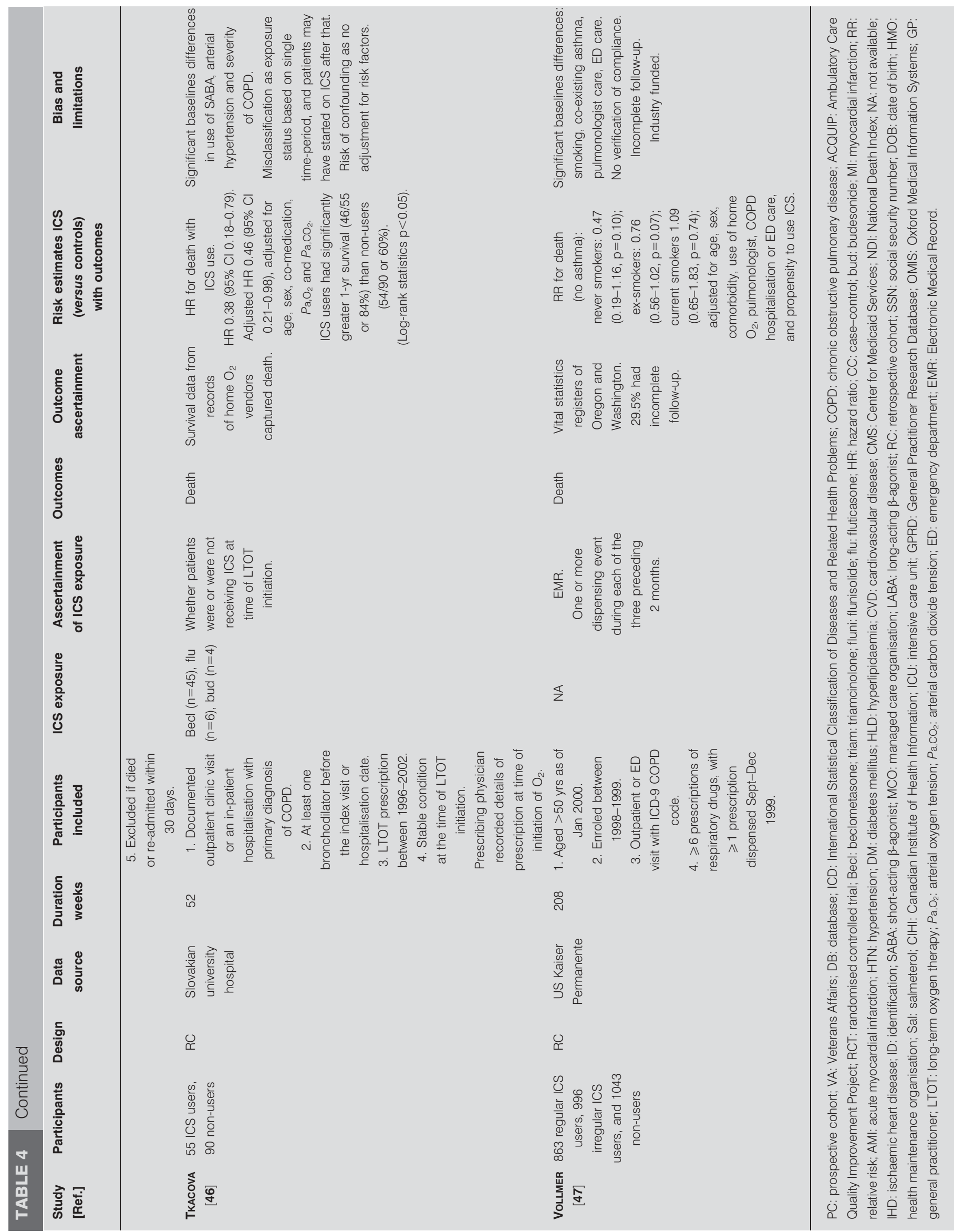




\begin{tabular}{lcc} 
Study [Ref.] & Weight $\%$ & Risk ratio \\
\cline { 3 - 3 } $\begin{array}{l}\text { a) } \\
\text { MACIE [5] }\end{array}$ & 6.5 & $0.62(0.43-0.89)$ \\
LEE [4] & 93.5 & $0.80(0.73-0.88)$ \\
Total & 100 & $0.79(0.72-0.86)$ \\
& & \\
b) SIN [43] & & \\
SORIANO [45] & 10.5 & $0.71(0.65-0.78)$ \\
FAN [38] & 0.1 & $0.81(0.31-2.15)$ \\
SIN [42] & 1.5 & $0.86(0.67-1.10)$ \\
SORIANO [44] & 11.7 & $0.75(0.69-0.82)$ \\
MACIE [5] & 0.9 & $0.62(0.45-0.85)$ \\
MAPEL [40] & 2.5 & $0.75(0.62-0.91)$ \\
TKACOVA [46] & 1.2 & $0.59(0.45-0.78)$ \\
MAPEL [41] & 0.2 & $0.46(0.22-0.98)$ \\
VoLLMER [47] & 1.9 & $0.76(0.61-0.95)$ \\
LeE [4] & 1.1 & $0.76(0.57-1.02)$ \\
Total & 68.5 & $0.80(0.77-0.83)$ \\
& & \\
& 100 & $0.78(0.75-0.80)$
\end{tabular}

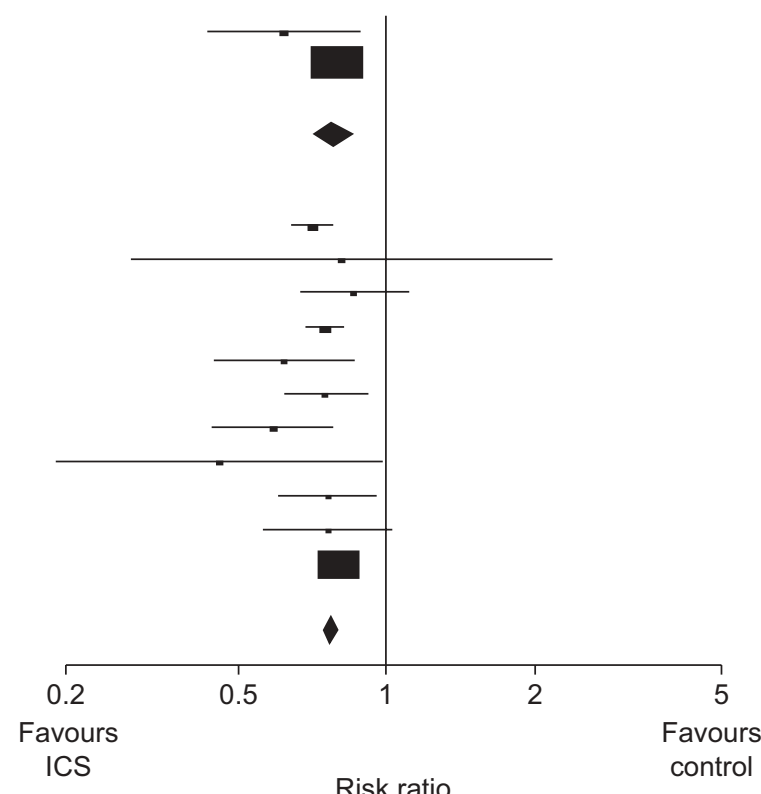

FIGURE 4. Meta-analysis of inhaled corticosteroids (ICS) versus controls for a) cardiovascular death and b) overall mortality in observational studies. a) Chisquared=1.79; degrees of freedom $(d f)=1(p=0.18) ; l^{2}=44 \%$. Test for overall effect: $z=5.10(p<0.00001)$. b) Chi-squared $=14.95 ; d f=10(p=0.13) ; I^{2}=33 \%$. Test for overall effect: $z=16.22(p<0.00001)$. IV: inverse variance.
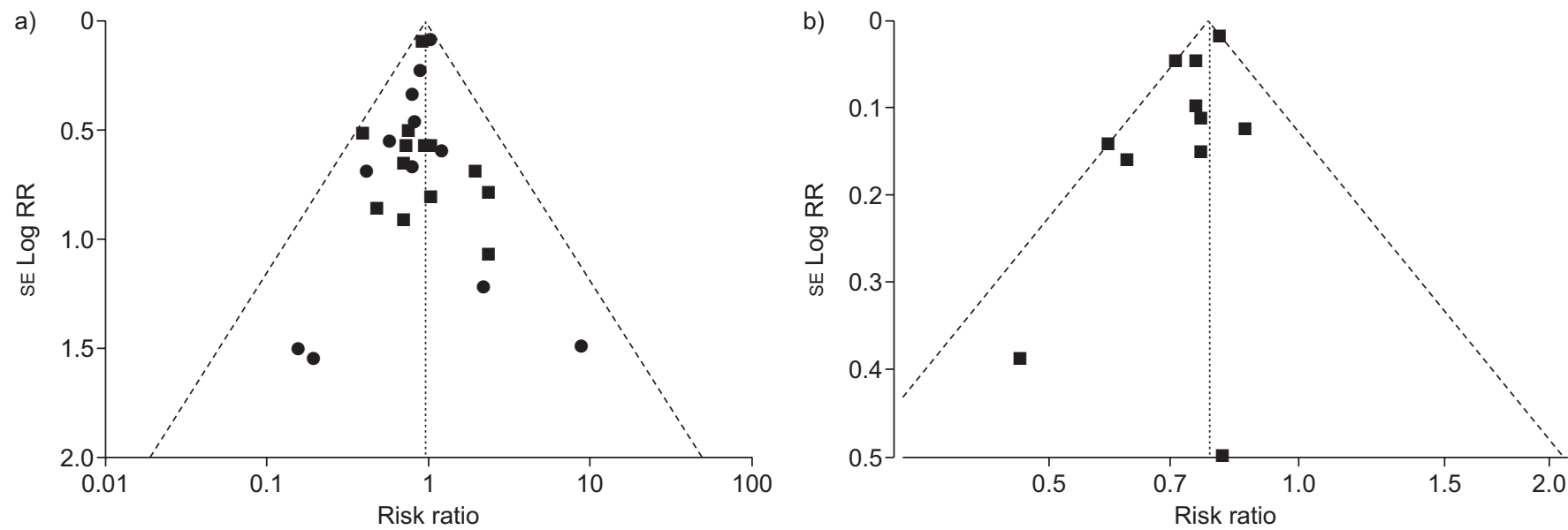

FIGURE 5. Funnel plots of risk ratios for overall mortality in the a) trials and b) observational studies, versus LABA; •: ICS versus placebo.

funding. There were no sources of funding for this work. No specific financial interests and relationships and affiliations relevant to the subject of their manuscript were reported by Y.K. Loke, C.S. Kwok and S. Singh. S. Singh is supported by the Johns Hopkins Clinical Research Scholars Program (Baltimore, MD, USA). Funding for this study was provided by grant number 1KL2RR025006-03 from the National Center for Research Resources (NCRR), a component of the National Institutes of Health (NIH), and NIH Roadmap for Medical Research. The contents of the study are solely the responsibility of the authors and do not necessarily represent the official view of NCRR or NIH.

\section{STATEMENT OF INTEREST}

None declared.

\section{ACKNOWLEDGEMENTS}

We would like to thank J. Vestbo (North West Lung Centre, University of Manchester, Manchester, UK) and S. Aaron (University of Ottawa, $\mathrm{ON}$, Canada) for providing data related to the subject of the manuscript.

\section{REFERENCES}

1 Suissa S, McGhan R, Niewoehner D, et al. Inhaled corticosteroids in chronic obstructive pulmonary disease. Proc Am Thorac Soc 2007; 4: 535-542.

2 Global Initiative for Chronic Obstructive Lung Disease. Global Strategy for the Diagnosis, Management and Prevention of 
Chronic Obstructive Pulmonary Disease. Available from www. goldcopd.com/Guidelineitem.asp? $11=2 \& 12=1 \&$ intId $=2003$

3 Sin DD, Paul Man SF. Cooling the fire within: inhaled corticosteroids and cardiovascular mortality in COPD. Chest 2006; 130: 629-631.

4 Lee TA, Pickard AS, Au DH, et al. Risk for death associated with medications for recently diagnosed chronic obstructive pulmonary disease. Ann Intern Med 2008; 149: 380-390.

5 Macie C, Wooldrage K, Manfreda J, et al. Inhaled corticosteroids and mortality in COPD. Chest 2006; 130: 640-646.

6 Curkendall SM, DeLuise C, Jones JK, et al. Cardiovascular disease in patients with chronic obstructive pulmonary disease, Saskatchewan Canada cardiovascular disease in COPD patients. Ann Epidemiol 2006; 16: 63-70.

7 Singh S, Amin AV, Loke YK. Long-term use of inhaled corticosteroids and the risk of pneumonia in chronic obstructive pulmonary disease: a meta-analysis. Arch Intern Med 2009; 169: 219-229.

8 GlaxoSmithKline clinical trials register. Result summaries: Compounds. Available from: www.gsk-clinicalstudyregister.com/ result_compounds.jsp

9 Astra Zeneca Clinical Trials register. Transparency of data. Available from: www.astrazenecaclinicaltrials.com/clinicaltrials

10 Loke YK, Price D, Herxheimer A. Adverse effects. In: Higgins JPT, Green S, eds. Cochrane Handbook for Systematic Reviews of Interventions. Version 5.02. Available from: www.cochrane-handbook. org

11 Egger M, Davey Smith G, Schneider $M$, et al. Bias in metaanalysis detected by a simple, graphical test. BMJ 1997; 315: 629-634.

12 Singh S, Loke YK, Furberg CD. Inhaled anticholinergics and risk of major adverse cardiovascular events in patients with chronic obstructive pulmonary disease: a systematic review and metaanalysis. JAMA 2008; 300: 1439-1450.

13 Higgins JP, Thompson SG, Deeks JJ, et al. Measuring inconsistency in meta-analyses. BMJ, 2003; 327: 557-560.

14 Davies HT, Crombie IK, Tavakoli M. When can odds ratios mislead?, BMJ 1998; 316: 989-991.

15 Aaron SD, Vandemheen KL, Fergusson D, et al. Tiotropium in combination with placebo, salmeterol, or fluticasone-salmeterol for treatment of chronic obstructive pulmonary disease: a randomized trial. Ann Intern Med 2007; 146: 545-555.

16 Burge PS, Calverley PM, Jones PW, et al. Randomised, double blind, placebo controlled study of fluticasone propionate in patients with moderate to severe chronic obstructive pulmonary disease: the ISOLDE trial. BMJ 2000; 320: 1297-1303.

17 Calverley P, Pauwels R, Vestbo J, et al. Combined salmeterol and fluticasone in the treatment of chronic obstructive pulmonary disease: a randomised controlled trial. Lancet 2003; 361: 449-456.

18 Calverley PM, Anderson JA, Celli B, et al. Salmeterol and fluticasone propionate and survival in chronic obstructive pulmonary disease. $N$ Engl J Med 2007; 356: 775-789.

19 Calverley PM, Boonsawat W, Cseke Z, et al. Maintenance therapy with budesonide and formoterol in chronic obstructive pulmonary disease. Eur Respir J 2003; 22: 912-919.

20 Ferguson GT, Anzueto A, Fei R, et al. Effect of fluticasone propionate/salmeterol (250/50 microg) or salmeterol (50 microg) on COPD exacerbations. Respir Med 2008; 102: 1099-1108.

21 GlaxoSmithKline. Study No. FLTA3025. Available from: www. gsk-clinicalstudyregister.com/files/pdf/1231.pdf

22 GlaxoSmithKline. Study No. SCO100250. Available from: www. gsk-clinicalstudyregister.com/files/pdf/3452.pdf

23 GlaxoSmithKline. Study No. SCO40041. Available from: www. gsk-clinicalstudyregister.com/files/pdf/21086.pdf

24 GlaxoSmithKline. Study No. SCO100470. Available from: www. gsk-clinicalstudyregister.com/files/pdf/1079.pdf
25 GlaxoSmithKline. Study No. SFCT01/SCO30002. Available from: www.gsk-clinicalstudyregister.com/files/pdf/23674.pdf

26 Hanania NA, Darken P, Horstman D, et al. The efficacy and safety of fluticasone propionate ( $250 \mathrm{microg}$ )/salmeterol (50 microg) combined in the Diskus inhaler for the treatment of COPD. Chest 2003; 124: 834-843.

27 Kardos P, Wencker M, Glaab T, et al. Impact of salmeterol/ fluticasone propionate versus salmeterol on exacerbations in severe chronic obstructive pulmonary disease. Am J Respir Crit Care Med 2007; 175: 144-149.

28 Lofdahl CG, Postma DS, Pride NB, et al. Possible protection by inhaled budesonide against ischemic cardiac events in mild COPD. Eur Respir J 2007; 29: 1115-1119.

29 Lung Health Study Research Group. Effect of inhaled triamcinolone on the decline in pulmonary function in chronic obstructive pulmonary disease. N Engl J Med 2000; 343: 1902-1909.

30 Mahler DA, Wire P, Horstman D, et al. Effectiveness of fluticasone propionate and salmeterol combination delivered via the Diskus device in the treatment of chronic obstructive pulmonary disease. Am J Respir Crit Care Med 2002; 166: 1084-1091.

31 Paggiaro PL, Dahle R, Bakran I, et al. Multicenter randomised placebo-controlled trial of inhaled fluticasone propionate in patients with chronic obstructive pulmonary disease. International COPD Study Group. Lancet 1998; 351: 773-780.

32 Rennard SI, Tashkin DP, McElhattan J, et al. Efficacy and tolerability of budesonide/formoterol in one hydrofluoroalkane pressurized metered-dose inhaler in patients with chronic obstructive pulmonary disease: results from a 1-year randomized controlled clinical trial. Drugs 2009; 69: 549-565.

33 Szafranski W, Cukier A, Ramirez A, et al. Efficacy and safety of budesonide/formoterol in the management of chronic obstructive pulmonary disease. Eur Respir J 2003; 21: 74-81.

34 Tashkin DP, Rennard SI, Martin P, et al. Efficacy and safety of budesonide and formoterol in one pressurized metered-dose inhaler in patients with moderate to very severe chronic obstructive pulmonary disease: results of a 6-month randomized clinical trial. Drugs 2008; 68: 1975-2000.

35 van der Valk P, Monninkhof E, van der Palen J, et al. Effect of discontinuation of inhaled corticosteroids in patients with chronic obstructive pulmonary disease: the COPE study. Am J Respir Crit Care Med 2002; 166: 1358-1363.

36 Vestbo J, Sorensen T, Lange $\mathrm{P}$, et al. Long-term effect of inhaled budesonide in mild and moderate chronic obstructive pulmonary disease: a randomised controlled trial. Lancet 1999; 353: 1819-1823.

37 Wouters EF, Postma DS, Fokkens B, et al. Withdrawal of fluticasone propionate from combined salmeterol/fluticasone treatment in patients with COPD causes immediate and sustained disease deterioration: a randomised controlled trial. Thorax 2005; 60: 480-487.

38 Fan VS, Bryson CL, Curtis JR, et al. Inhaled corticosteroids in chronic obstructive pulmonary disease and risk of death and hospitalization: time-dependent analysis. Am J Respir Crit Care Med 2003; 168: 1488-1494.

39 Huiart L, Ernst P, Ranouil X, et al. Low-dose inhaled corticosteroids and the risk of acute myocardial infarction in COPD. Eur Respir J 2005; 25: 634-639.

40 Mapel DW, Hurley JS, Roblin D, et al. Survival of COPD patients using inhaled corticosteroids and long-acting beta agonists. Respir Med 2006; 100: 595-609.

41 Mapel DW, Nelson LS, Lydick E, et al. Survival among COPD patients using fluticasone/salmeterol in combination versus other inhaled steroids and bronchodilators alone. COPD 2007; 4: 127-134.

42 Sin DD, Man SF. Inhaled corticosteroids and survival in chronic obstructive pulmonary disease: does the dose matter? Eur Respir $J$ 2003; 21: 260-266. 
43 Sin DD, Tu JV. Inhaled corticosteroids and the risk of mortality and readmission in elderly patients with chronic obstructive pulmonary disease. Am J Respir Crit Care Med 2001; 164: 580-584.

44 Soriano JB, Kiri VA, Pride NB, et al. Inhaled corticosteroids with/without long-acting beta-agonists reduce the risk of rehospitalization and death in COPD patients. Am J Respir Med 2003; 2: 67-74.

45 Soriano JB, Vestbo J, Pride NB, et al. Survival in COPD patients after regular use of fluticasone propionate and salmeterol in general practice. Eur Respir J 2002; 20: 819-825.

46 Tkacova R, Toth S, Sin DD. Inhaled corticosteroids and survival in COPD patients receiving long-term home oxygen therapy. Respir Med 2006; 100: 385-392.

47 Vollmer WM, Peters D, Crane B, et al. Impact of regular inhaled corticosteroid use on chronic obstructive pulmonary disease outcomes. COPD 2007; 4: 135-142.

48 Hopewell S, Loudon K, Clarke MJ, et al. Publication bias in clinical trials due to statistical significance or direction of trial results. Cochrane Database Syst Rev 2009; 1: MR000006.

49 Suissa S. Effectiveness of inhaled corticosteroids in chronic obstructive pulmonary disease: immortal time bias in observational studies. Am J Respir Crit Care Med 2003; 168: 49-53.

50 Sin DD, Wu L, Anderson JA, et al. Inhaled corticosteroids and mortality in chronic obstructive pulmonary disease. Thorax 2005; 60: 992-997.

51 Yang IA, Fong KM, Sim EH, et al. Inhaled corticosteroids for stable chronic obstructive pulmonary disease. Cochrane Database Syst Rev 2007; 2: CD002991.

52 Drummond MB, Dasenbrook EC, Pitz MW, et al. Inhaled corticosteroids in patients with stable chronic obstructive pulmonary disease: a systematic review and meta-analysis. JAMA 2008; 300: 2407-2416.

53 Wedzicha JA, Seemungal TA, MacCallum PK, et al. Acute exacerbations of chronic obstructive pulmonary disease are accompanied by elevations of plasma fibrinogen and serum IL-6 levels. Thromb Haemost 2000; 84: 210-215.

54 Barnes PJ, Celli BR. Systemic manifestations and comorbidities of COPD. Eur Respir J 2009; 33: 1165-1185.

55 Sin DD, Man SF, Marciniuk DD, et al. The effects of fluticasone with or without salmeterol on systemic biomarkers of inflammation in chronic obstructive pulmonary disease. Am J Respir Crit Care Med 2008; 177: 1207-1214.

56 Janda S Park K, Fitzgerald JM, et al. Statins in COPD: a systematic review. Chest 2009; 136: 734-743.

57 Rodrigo GJ, Castro-Rodriguez JA, Plaza V. Safety and efficacy of combined long-acting beta-agonists and inhaled corticosteroids vs long-acting beta-agonists monotherapy for stable COPD: a systematic review. Chest 2009; 136: 1029-1038.

58 Postma DS, Calverley P. Inhaled corticosteroids in COPD: a case in favour. Eur Respir J 2009; 34: 10-12.

59 Suissa S, Barnes PJ. Inhaled corticosteroids in COPD: the case against. Eur Respir J 2009; 34: 13-16.

60 Suissa S, Ernst P, Vandemheen KL, et al. Methodological issues in therapeutic trials of COPD. Eur Respir J 2008; 31: 927-933.

61 Ford PA, Russell RE, Barnes PJ. ICS and COPD: time to clear the air. Int J Chron Obstruct Pulmon Dis 2009; 4: 289-290.

62 Sin DD, Tashkin D, Zhang $X$, et al. Budesonide and the risk of pneumonia: a meta-analysis of individual patient data. Lancet 2009; 374: 712-719.

63 Singh S, Loke YK. Risk of pneumonia associated with long-term use of inhaled corticosteroids in chronic obstructive pulmonary disease: a critical review and update. Curr Opin Pulm Med 2010; 16: 118-122.

64 Ferguson GT, Calverley PM, Anderson JA, et al. Prevalence and progression of osteoporosis in patients with COPD. Results from TORCH. Chest 2009; 136: 1456-1465. 